\section{Dementia

Published online: January 20, 2011

\title{
The Unparalleled Challenge of Aging Populations
}

Two thirds of the world's population live in the Asia-Pacific region, where the population is aging rapidly. Of the estimated 24.3 million persons with dementia living today, most are found in rapid growth nations like India, China and the surrounding Western-Pacific and South-Asian countries [Ferri CP, et al: Lancet 2005;366:2112-2117]. Here the numbers of persons with dementia are expected to increase fourfold between 2001 and 2040. The burden of dementia with its major medical, social and economic challenges in Asian-Pacific countries is unparalleled in the world. As governments and societies rise to the challenges of ageing populations and dementia, are researchers in the region paving the way to help solve a global problem by providing information that guide policy decisions and clinical practice? The research published in this special issue shows that investigators in China, India, Japan, Korea, Malaysia, Singapore and Australia are indeed addressing research issues in dementia and cognitive disorders in the elderly population with vigor and ingenuity. The cutting edge of research in Australia is as expected, but gratifying advances are being made in the rest of Asia, too.

The research topics in this issue span the range from basic clinical science to epidemiology and dementia care delivery. The ethnic and cultural diversity of the populations studied in this collection of works is particularly interesting and remarkable, and speaks of the diversity in economic, demographic, religious, cultural and geo-political characteristics in the countries where the research was conducted. As countries in the Asia Pacific make rapid strides in economic and social developments, their growing research efforts and their contributions will enrich the field of dementia research and further advance understandings and solutions globally.

Prof. T.-P. Ng

Guest Editor

\section{KARGER}

Fax +4161306 1234

E-Mail karger@karger.ch

www.karger.com (c) 2011 S. Karger AG, Basel

1420-8008/10/0306-0454\$26.00/0

Accessible online at: www.karger.com/dem 